\title{
Development of Shaft-type Scrap Melting Process Characterized by Massive Coal and Plastics Injection
}

\author{
Tatsuro ARIYAMA, Masahiro MATSUURA, Hidetoshi NODA, Minoru ASANUMA, \\ Tsutomu SHIKADA, Ryota MURAI, Hiromi NAKAMURA ${ }^{1)}$ and Takashi SUMIGAMA ${ }^{2)}$
}

Materials and Processing Research Center, NKK Corporation, Kokan-cho, Fukuyama, Hiroshima-ken, 721 Japan.

1) Keihin Works, NKK Corporation, Minamiwatarida, Kawasaki-ku, Kawasaki, Kanagawa-ken, 210 Japan.

2) Steel Technical Center, NKK Corporation, Marunouchi, Chiyoda-ku,Tokyo, 100 Japan.

(Received on April 9, 1997; accepted in final form on July 4, 1997)

\begin{abstract}
A shaft-type scrap melting process in which a large amount of pulverized coal and waste plastics are used as a heat source has been newly proposed. To confirm the characteristics of this process, an experimental furnace with $2 \mathrm{~m}^{3}$ inner volume was continuously operated. The main results are as follows:

(1) Pulverized coal and plastics could be effectively used to melt steel scrap, and a newly designed oxygen burner enabled massive injection of such fuels.

(2) Combustion efficiency of coarse plastics was higher than pulverized coal due to the its accumulation effect in the raceway. Hydrogen chloride during polyvinylchloride injection was about $5 \mathrm{ppm}$ in the gas cleaning system.

(3) Top charge of plastics generated tar derived from decomposition of plastics in the shaft with low temperature.

(4) Zinc charged with scrap was carried over as zinc oxide with dust in the upward gas, and no adhesion was recognized within the furnace.

(5) Maximum productivity was estimated to be $14 \mathrm{t} / \mathrm{dm}^{3}$ from the viewpoints of flooding and melting rate of scrap.

On the basis of the above operation results of the experimental furnace, the operating condition of the commercial process was investigated.
\end{abstract}

KEY WORDS: scrap melting; shaft furnace; pulverized coal; waste plastics; plastics injection; oxygen burner; raceway.

\section{Introduction}

Recently, the reclamation of steel scrap has attracted special interest as a way to promote the effective utilization of steel resources. Similarly, from the viewpoints of environmental issues and the use of resources, an increasing amount of attention has been directed at the recycling of waste plastics contained within municipal and industrial wastes. In these circumstances, it is expected that steelworks will come to play an important role in the recycling of the resources and the waste generated in nearby cities.

Just as pulverized coal is commonly utilized in the blast furnace as an auxiliary fuel, it is conceivable that the waste plastics contained within municipal and industrial waste could be effectively used as a heat source. A process by which steel scrap could be melted in a thermally efficient shaft furnace using pulverized coal and waste plastics as a main energy source would be highly beneficial and favorable from the standpoint of recycling. Furthermore, by blowing oxygen through the tuyeres instead of hot blast, it would be possible not only to use a large amount of pulverized coal and waste plastics as fuel, but also to recover a nitrogen-free high calorie top gas for use in power generation and the like.

From this background as described above, a shaft-type scrap melting process that can use a large amount of pulverized coal and waste plastics has been newly developed. To confirm the characteristics of the process, a continuous test operation using a $2 \mathrm{~m}^{3}$ inner volume experimental shaft furnace was conducted for one and half months. Through the operation with the experimental furnace, the influence of injected pulverized coal and plastics on the operation, the properties of the top gas and dusts, the melting behavior of scrap and the limitation of the productivity were investigated. Finally, on the basis of the operation results, the commercial feasibility of this process was studied.

\section{Conception of the Process}

Figure 1 shows a conceptual outline of the process. Scrap and a suitable amount of coke are charged to the top of furnace; and pulverized coal and waste plastics are blown in through the tuyeres with cold oxygen. Use of pure oxygen makes it possible to inject a large amount 


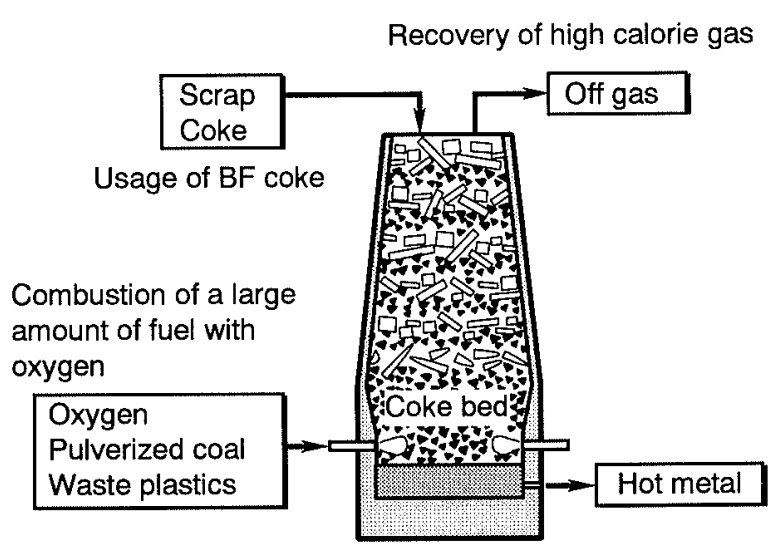

Fig. 1. Conception of the scrap melting process.

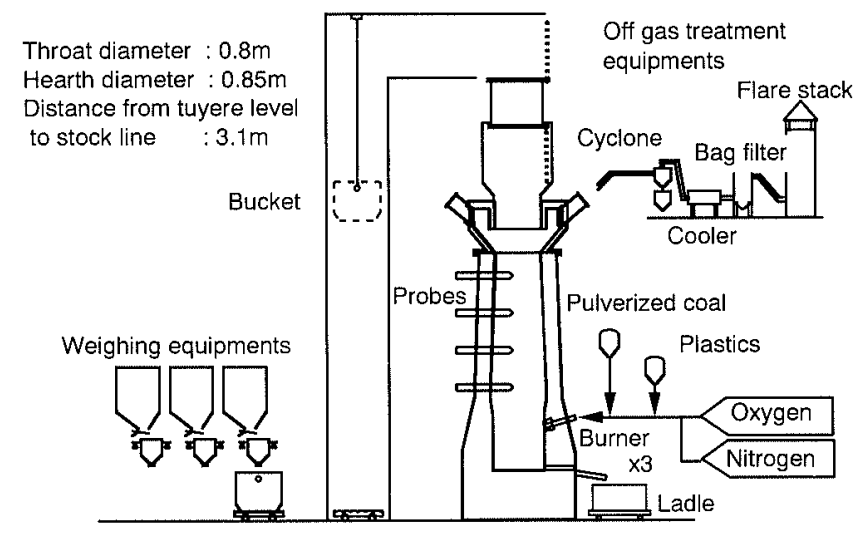

Fig. 2. Experimental shaft furnace.

of coal and plastics. High calorie nitrogen free gas is recovered from the top of the furnace, and can be used in power generation.

A cupola ${ }^{1)}$ is similar to this process. However, in this process, blast furnace coke is used instead of large diameter foundry coke, so that a raceway can be formed to achieve a high rate injection of fuels and the oxidation degree can be kept low for the recovery of top gas. Moreover, although a method with post combustion in the shaft to decrease the fuel rate was proposed, ${ }^{2)}$ the process in this paper was so designed instead to give priority to the recovery of high calorie gas. The injection of waste plastics in the commercial blast furnace has been just started in Germany, ${ }^{3)}$ however, the amount of injected plastics stays in the limited region like $35 \mathrm{~kg} / \mathrm{t}$. The experiment on massive injection of pulverized coal and plastics over $100 \mathrm{~kg} / \mathrm{t}$ in the scrap melting process has not been tried yet. The scrap melting process proposed in this paper is characterized by the massive coal and plastics injection. To achieve effective combustion of pulverized coal and plastics in the raceway, originally developed oxygen burners were applied.

\section{Experimental Shaft Furnace}

Figure 2 shows the experimental shaft furnace used for the verification of this process. Unlike that of a cupola, the furnace top has a double sealing structure to isolate the top gas from the atmospheric air. In addition, the seal valve is airtight and allows the charging of large

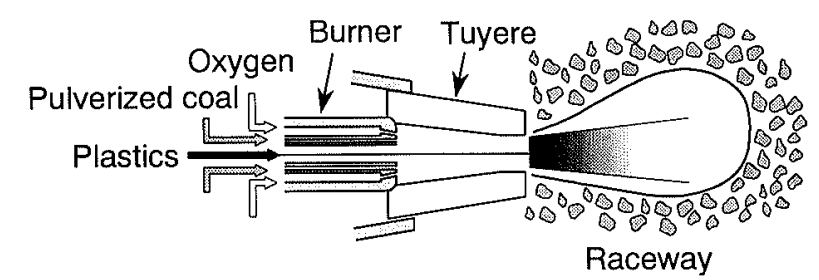

Tuyere diameter $100 \mathrm{~mm} \phi$

Fig. 3. Oxygen burner of the scrap melting shaft furnace.

Table 1. Properties of raw materials and fuels (PE: Polyethylene, PS: Polystyrene, PVC: Polyvinylchloride).

\begin{tabular}{l|c}
\hline $\begin{array}{l}\text { Steel scrap } \\
\text { (size, weight) }\end{array}$ & $\begin{array}{c}\text { Shredded } 30-60 \mathrm{~mm} \\
: 0.02-0.08 \mathrm{~kg} / \mathrm{p}\end{array}$ \\
$\begin{array}{l}\text { Heavy plate }:-200 \mathrm{~mm} \\
: 0.2-3.4 \mathrm{~kg} / \mathrm{p}\end{array}$ \\
\hline Coke & $20-40 \mathrm{~mm}$ \\
\hline $\begin{array}{l}\text { Pulverized } \\
\text { coal }\end{array}$ & $-200 \mathrm{mesh} 80 \%$ \\
& $\begin{array}{l}\text { PE: }-1 \mathrm{~mm}, 2-4 \mathrm{~mm} \\
\text { Plastics }\end{array}$ \\
& $\begin{array}{l}\text { PSibered PE: } 2-4 \mathrm{~mm} \\
\text { PVC: }-1 \mathrm{~mm}\end{array}$ \\
\hline
\end{tabular}

pieces of scrap. The effective inner volume is $2 \mathrm{~m}^{3}$. The inner wall of the shaft furnace is lined with refractory. The top gas dust is collected by the cyclone and bag filter. In order to measure the temperature distribution in the furnace, measuring probes are installed at four vertical positions, and in-furnace dust can also be sampled by these probes.

This furnace has three tuyeres, all of which are equipped with an oxygen burner as shown in Fig. 3 . Pulverized coal and plastics are blown to the tip of the burner through the independent lines. The burner uses a concentric tube arrangement to blow the fuels and oxygen so that these fuels and the oxygen can be rapidly mixed in the raceway, and oxygen is blown through the multi-holes at a high speed to cover the fuels. The basic design and characteristics of the burner is similar to those of burner applied to the oxygen blast furnace. ${ }^{4)}$ In the experimental furnace, nitrogen is purposely used to control the flame temperature due to its easiness of control. However, in the commercial furnace, steam is used to avoid the decrease of the top gas heat content.

The properties of the scrap and fuels used in the operation are shown in Table 1. As for the scrap, sizes ranging from 30 to $60 \mathrm{~mm}$ of shredded scrap were takes as standard, and heavy plate of $-200 \mathrm{~mm}$ were also used for a short period. Coke size was from 20 to $40 \mathrm{~mm}$. The particle size and properties of plastics were varied over a wide range as shown in Table 1. The maximum particle size chosen for the experimental furnace was $4 \mathrm{~mm}$ in diameter. The particle size of pulverized coal was -200 mesh $(-74 \mu \mathrm{m}) 80 \%$, the same as for a blast furnace. The chemical properties of pulverized coal and plastics were shown in Table 2. 
Table 2. Chemical properties of pulverized coal and plastics.

\begin{tabular}{l|cccccc|c}
\hline & \multicolumn{5}{|c|}{$\begin{array}{c}\text { Ultimate analysis (mass\%) } \\
\text { (dry base) }\end{array}$} & $\begin{array}{c}\text { Calorific value } \\
\text { (MJ/kg) }\end{array}$ \\
\hline & $\mathrm{C}$ & $\mathrm{H}$ & $\mathrm{N}$ & $\mathrm{O}$ & $\mathrm{S}$ & $\mathrm{Cl}$ & \\
\hline Coke & 87.4 & 0.3 & 0.1 & - & 0.5 & - & 32.6 \\
Pulverized coal & 75.1 & 5.5 & 1.6 & 13.4 & 0.5 & - & 28.9 \\
Polyethylene & 84.8 & 14.1 & - & - & - & - & 44.1 \\
Polystyrene & 87.9 & 7.9 & - & - & - & - & 39.7 \\
Polyvinylchioride & 43.7 & 5.6 & - & 2.6 & 1.2 & 49.2 & 22.1 \\
\hline
\end{tabular}

Table 3. Operating results of all-coke and pulverized coal injeclion.

\begin{tabular}{|c|c|c|c|}
\hline & All-Coke & \multicolumn{2}{|c|}{$\mathrm{PCl}$} \\
\hline Productivity (t/d) & 10.1 & 10.5 & 10.8 \\
\hline Fuel rate $(\mathrm{kg} / \mathrm{t})$ & 600 & 690 & 690 \\
\hline Coke rate $(\mathrm{kg} / \mathrm{t})$ & 600 & 400 & 300 \\
\hline PC $\quad(\mathbf{k g} / \mathrm{t})$ & - & 290 & 390 \\
\hline Blast & & & \\
\hline Oxygen $\left(\mathrm{Nm}^{3} / \mathrm{t}\right)$ & 419 & 423 & 417 \\
\hline Nitrogen $\left(\mathrm{Nm}^{3} / \mathrm{t}\right)$ & 939 & 359 & 115 \\
\hline Flame temp. $\left({ }^{\circ} \mathrm{C}\right)$ & 2230 & 2310 & 2390 \\
\hline Top gas comp. & & & \\
\hline Co (vol\%) & 43.5 & 52.3 & 59.9 \\
\hline $\mathrm{CO}_{2}(\mathrm{vol} \%)$ & 2.4 & 1.5 & 4.4 \\
\hline $\mathrm{H}_{2} \quad$ (vol\%) & 0.7 & 10.2 & 12.1 \\
\hline $\begin{array}{l}\text { Hot metal } \\
\text { temp. }\left({ }^{\circ} \mathrm{C}\right)\end{array}$ & 1370 & 1360 & 1310 \\
\hline C $\quad(\operatorname{mass} \%)$ & 4.08 & 4.23 & 4.04 \\
\hline Si (mass \%) & 1.30 & 1.27 & 0.72 \\
\hline
\end{tabular}

\section{Operation Results of Pulverized Coal and Plastics Injection}

\subsection{Pulverized Coal Injection}

The experimental furnace operation for one condition was continued for about three days; when it was confirmed to be in a steady state, various operating data were taken and the furnace was then continuously set for the next operation. Through these operations, the productivity was maintained at 10 to $12 \mathrm{t} / \mathrm{d}$ level as standard.

Table 3 shows the representative results for all-coke operation of a standard and a pulverized coal injection operation. The top gas oxidation degree was, as predicted earlier, less than $10 \%$, while $\mathrm{CO}_{2}$ in the top gas was evaluated to be caused by decomposition of limestone charged as flux. The hot metal temperature is about $1350^{\circ} \mathrm{C}$. Although this value is lower than that in a commercial blast furnace, it is average one in this experimental furnace due to the relative high heat-loss after the tap-hole. The hot metal composition is similar to that of a blast furnace. However, silicon content in the hot metal is much higher than that in a blast furnace, because the fuel rate of this furnace is set to a relative high value. Slag rate is much lower than in a blast furnace; in fact that is about $100 \mathrm{~kg} / \mathrm{t}$ in this furnace. Even in the case of a high rate coal injection over $300 \mathrm{~kg} / \mathrm{t}$, a favorable operation could be attained, however hot metal temperature had a tendency to decrease as shown in Table 3. Generally, as a result of this operation, it was possible to simultaneously achieve a high rate injection of pulverized coal and sufficient scrap melting.

Figure 4 shows the relation between combustion efficiency and the oxygen excess ratio determined by

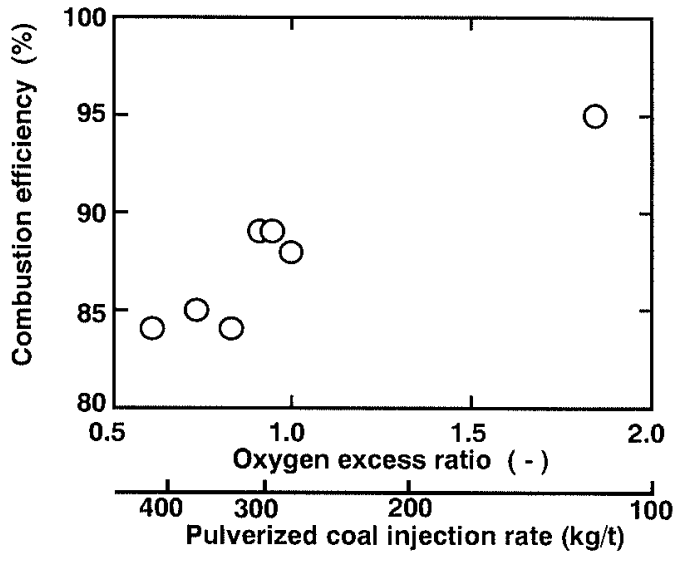

Fig. 4. Relation between combustion efficiency of pulverized coal and oxygen excess ratio.

the carbon and hydrogen balance in the furnace. Combustion efficiency is defined as the ratio of the gasified carbon and hydrogen to those contained in the pulverized coal. As the oxygen excess ratio becomes less than 1.0, the combustion efficiency gradually declines. In this condition, the amount of top gas dust increased. In the case of oxygen excess ratio over 1.0, top gas dust amounts to $20 \mathrm{~kg} / \mathrm{t}$. However, in the range of oxygen excess ratio less than 1.0 , it becomes beyond $50 \mathrm{~kg} / \mathrm{t}$. Then, almost of top gas dust consists of char derived from pulverized coal. That is, unlike what occurs in a blast furnace, a solution-loss reaction does not occur in the furnace; unburnt char is carried over from the top of the furnace. Replacement ratio of pulverized coal to coke decreases. Finally, as far as fuel rate was constant, the hot metal temperature became lower. On the basis of these results, it was evaluated that the practical limit of the coal injection rate was approximately $300 \mathrm{~kg} / \mathrm{t}$. However, this upper limit is much higher than in a conventional blast furnace.

\subsection{Plastics Injection}

Figure 5 shows the transition of operating results during simultaneous injection of plastics and pulverized coal. In these operations, fuel rate based on the calorific value of the injected fuels and the top gas temperature was kept constant, and flame temperature was predetermined to $2300^{\circ} \mathrm{C}$. The top gas temperature was kept to about $250^{\circ} \mathrm{C}$. Table 4 shows the representative operating results during these operations. From Fig. 5 and Table 4, it can be seen that plastics injection enabled stable operation without any drop in hot metal temperature, and no difficulties like pressure drop increase in the shaft furnace were experienced even in coarse plastics injection of 2-4 mm polyethylene (PE) particle. In particular, as shown in Fig. 5, injection of coarse plastics like 2-4 $\mathrm{mm}$ particle ensured the increase of hot metal temperature, except the unstable state period of plastics transportation. Moreover, it was found that the considerable exothermic energy of polystyrene (PS) which has a high ratio of carbon, was effectively utilized in the raceway to keep appreciable hot metal temperature.

Figure 6 shows the combustion efficiency for pulverized 


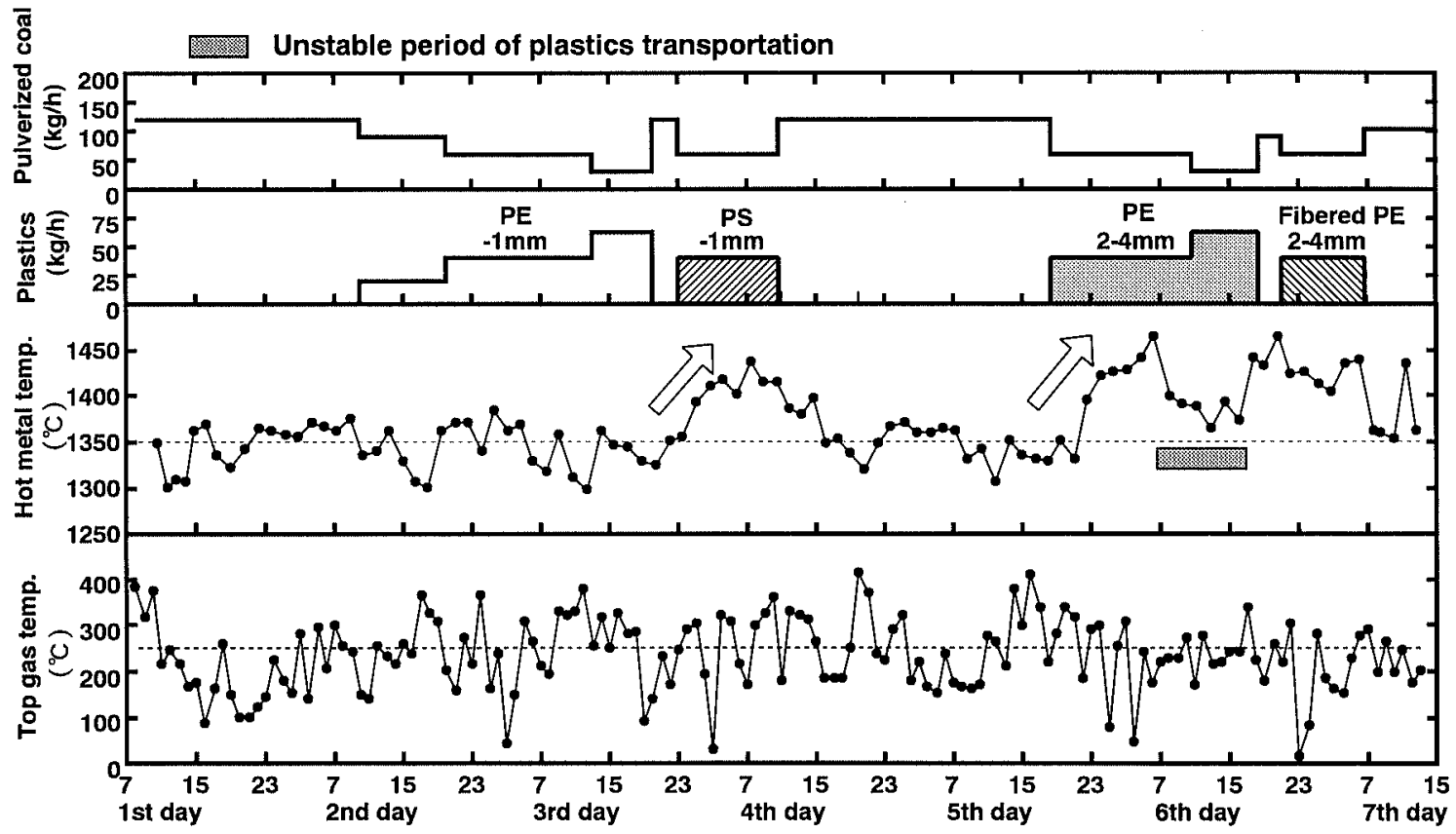

Time

Fig. 5. Trend of plastics injection operations in the scrap melting furnace.

Table 4. Operating results of plastics injection.

\begin{tabular}{|c|c|c|c|c|}
\hline & \multirow{2}{*}{ Base } & \multicolumn{3}{|c|}{ PC+Plastics } \\
\hline & & $\begin{array}{c}\text { PE } \\
-1 \mathrm{~mm}\end{array}$ & $\begin{array}{c}P E \\
2-4 \mathrm{~mm}\end{array}$ & $\begin{array}{c}\text { PS } \\
-1 \mathrm{~mm}\end{array}$ \\
\hline Productivity $(\mathrm{t} / \mathrm{d})$ & 10.1 & 11.3 & 11.1 & 11.8 \\
\hline $\begin{array}{l}\text { Fuel rate }(\mathbf{k g} / \mathbf{t}) \\
\text { Coke rate }(\mathbf{k g} / \mathrm{t}) \\
\text { PC } \quad(\mathbf{k g} / \mathbf{t}) \\
\text { Plastics } \quad(\mathbf{k g} / \mathbf{t})\end{array}$ & $\begin{array}{c}690 \\
400 \\
290 \\
-\end{array}$ & $\begin{array}{r}630 \\
400 \\
80 \\
150\end{array}$ & $\begin{array}{r}630 \\
400 \\
80 \\
150\end{array}$ & $\begin{array}{l}640 \\
400 \\
140 \\
100 \\
\end{array}$ \\
\hline $\begin{array}{l}\text { Blast } \\
\text { Oxygen }\left(\mathrm{Nm}^{3} / \mathrm{t}\right) \\
\text { Nitrogen }\left(\mathrm{Nm}^{3} / \mathrm{t}\right) \\
\text { Flame temp. }\left({ }^{\circ} \mathrm{C}\right)\end{array}$ & $\begin{array}{c}419 \\
939 \\
2230 \\
\end{array}$ & $\begin{array}{r}393 \\
293 \\
2360 \\
\end{array}$ & $\begin{array}{c}400 \\
291 \\
2270\end{array}$ & $\begin{array}{r}376 \\
386 \\
2390 \\
\end{array}$ \\
\hline $\begin{array}{cc}\text { Top gas comp. } \\
\mathrm{CO} & \text { (vol\%) } \\
\mathrm{CO}_{2} & (\text { vol\%) } \\
\mathrm{H}_{2} & (\text { vol\%) }\end{array}$ & $\begin{array}{r}52.3 \\
1.5 \\
10.2\end{array}$ & $\begin{array}{r}47.3 \\
3.3 \\
14.8\end{array}$ & $\begin{array}{r}46.0 \\
1.4 \\
15.4\end{array}$ & $\begin{array}{r}51.6 \\
3.2 \\
8.8\end{array}$ \\
\hline $\begin{array}{ll}\text { Hot metal } & \\
\text { temp. } & \left({ }^{\circ} \mathrm{C}\right) \\
\mathrm{C} & \text { (mass } \%) \\
\mathrm{Si} & \text { (mass } \%)\end{array}$ & $\begin{array}{r}1360 \\
4.23 \\
1.27\end{array}$ & $\begin{array}{r}1340 \\
4.19 \\
0.86\end{array}$ & $\begin{array}{r}1400 \\
4.51 \\
0.93\end{array}$ & $\begin{array}{r}1410 \\
4.45 \\
1.01\end{array}$ \\
\hline
\end{tabular}

coal and plastics of 2-4 mm polyethylene as determined from the carbon and hydrogen balance in the shaft furnace. These are cases in which pulverized coal and plastics were individually injected. From Fig. 6, it is noted that the combustion efficiency of coarse plastics like $2-4 \mathrm{~mm}$ polyethylene is higher than that of pulverized coal and it reaches a higher level.

According to the experimental results in the drop tube furnace carried out by authors, ${ }^{5}$ the combustion rate of a single plastic particle was lower than that of pulverized coal. However, in the operation results described above, plastics injection produces a higher combustion efficiency, even though plastics particles are of a larger size than pulverized coal. This deviation between the drop tube furnace and the above results in the shaft furnace is considered to be due to the formation of a raceway in

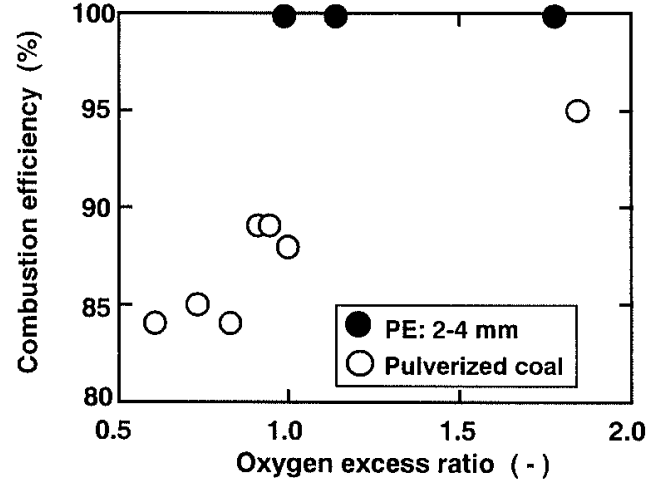

Fig. 6. Combustion efficiency of pulverized coal and plastics.

Pulverized Coal

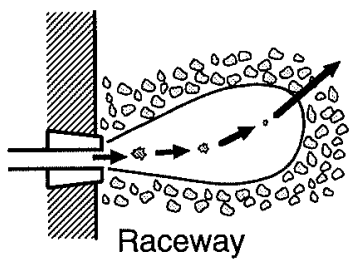

Coarse Plastics

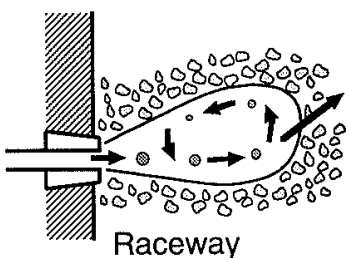

Fig. 7. Combustion mechanism of plastics and pulverized coal injected into the raceway.

the coke bed, whereby the coarse plastics are held within the raceway and burn out at a high efficiency.

The authors confirmed the behavior of coarse particle hold-up in the raceway by the cold model. ${ }^{6}$ ) The combustion mechanism of coarse plastics in the raceway can be represented as shown in Fig. 7, compared with pulverized coal injection. It appears that pulverized coal particles pass through the raceway instantaneously, while coarse plastics can stay in the raceway due to circulation effect. ${ }^{6)}$ As long as the condition for plastics particles 


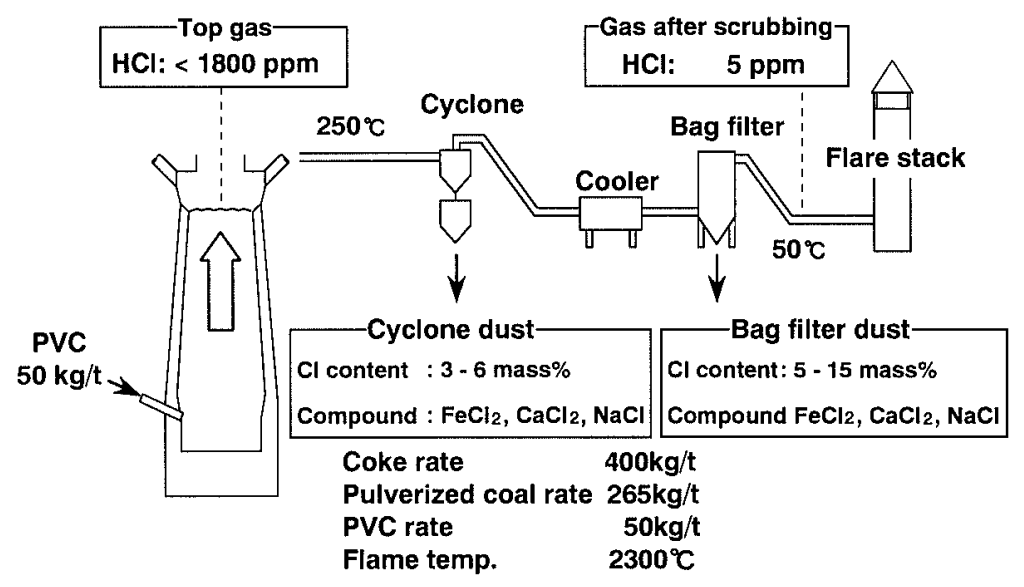

Fig. 8. Chlorine balance in polyvinylchloride injection.

holdup is satisfied in the raceway, plastics particles can attain high combustion efficiency. Besides the above cold model experiment, the combustion behavior of the coarse plastics in the raceway was analyzed with the hot model. ${ }^{7}$ ) The result of the hot model shows the tendency that the combustion efficiency of plastics becomes higher with increase of the particle diameter. It is estimated that the critical diameter of the particle which escapes from the raceway is determined by the terminal velocity at the boarder of the raceway, and the coarser plastics particle can keep the longer residence time due to the circulation until its diameter reduces to the critical diameter by combustion. ${ }^{7)}$ The plastics particle does not break up by the rapid heating in the raceway unlike the coal particle.

The above estimation agrees with the operating results as shown in Figs. 5 and 6, however, there remain many subjects to be confirmed on the combustion mechanism of the plastics injected into the raceway.

\subsection{Injection of Polyvinylchloride}

Polyvinylchloride (PVC) is frequently contained in municipal waste plastics. Hydrogen chloride generated from polyvinylchloride could cause a serious problem like corrosion in the gas cleaning system. To investigate the chlorine behavior in the furnace, polyvinylchloride was intentionally injected at the $50 \mathrm{~kg} / \mathrm{t}$ level during the operation of plastics injection. Polyvinylchloride is considered to take a form of hydrogen chloride in the furnace, and the calculated concentration of hydrogen chloride in the furnace is assumed to be $8000 \mathrm{ppm}$. The concentration of hydrogen chloride in the gas was frequently measured at the throat of the furnace and the gas cleaning system, and chlorides in the dust collected by the cyclone and the bag filter were analyzed.

The measured results are shown in Fig. 8. At the throat, the concentration of hydrogen chloride was less than $1800 \mathrm{ppm}$. On the other hand, it was extremely small at the exit of the bag filter position, that is, about $5 \mathrm{ppm}$, because at the location of the cyclone and bag filter, most of the chloride compound in the dust takes the form of $\mathrm{FeCl}_{2}, \mathrm{CaCl}_{2}$ and $\mathrm{NaCl}$. The top gas temperature was about $250^{\circ} \mathrm{C}$, and the gas temperature in the gas cleaning system dropped below $50^{\circ} \mathrm{C}$ by the gas cooler. Hydrogen chloride in the gas tends to react with ferrous compounds and alkali metals contained in the dust due to the contact

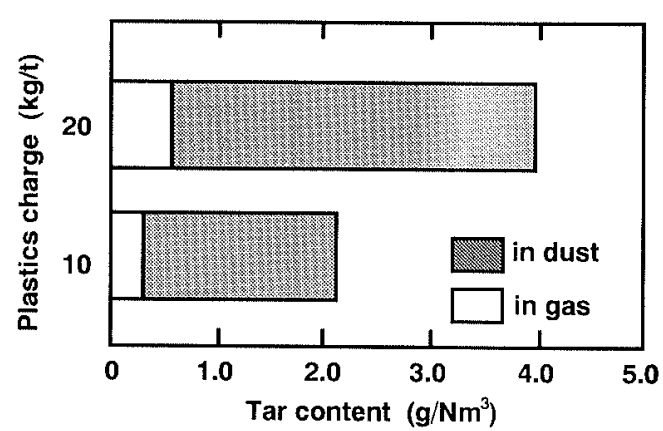

Fig. 9. Tar content in top gas and dust during top charge of plastics.

with dust and the decrease of gas temperature. Thus, during PVC injection, it was estimated that the quenching of the top gas is so effective to decrease the hydrogen chloride content by fixing in solid phase and to avoid the corrosion of gas cooling system.

\section{Top Charge of Plastics}

In order to inject plastics particles through the tuyere, plastics have to be pulverized to small particles. If the plastics are easily gasified in the shaft, top charging of plastics can be a possible way to treat waste plastics without grinding. However, it is feared that top charge of plastics generates tar due to the decomposition of plastics in the low temperature region of the shaft. To investigate the gasification behavior of plastics charged to the top, lumpy plastics of $20 \mathrm{~mm}$ were charged up to $20 \mathrm{~kg} / \mathrm{t}$. In this case, plastics do not act as a fuel for the furnace but as a source of high calorific top gas.

Tar in the top gas and dust was measured. Figure 9 shows the tar content in the top gas and dust measured during the top charge operation of plastics. Tar is defined as soluble material in Toluene. As shown in Fig. 9, in the top charge of plastics, total tar content in the top gas and dust cannot be disregarded, and amounts to about $4.0 \mathrm{~g} / \mathrm{Nm}^{3}$. In the case of tuyere injection of plastics, total tar content in the top gas and dust was negligible. Furthermore, to estimate the chemical structure of tar in the dust, the number of carbon in the tar was analyzed and is shown in Fig. 10. From these results, it was estimated that the tar in the dust con- 


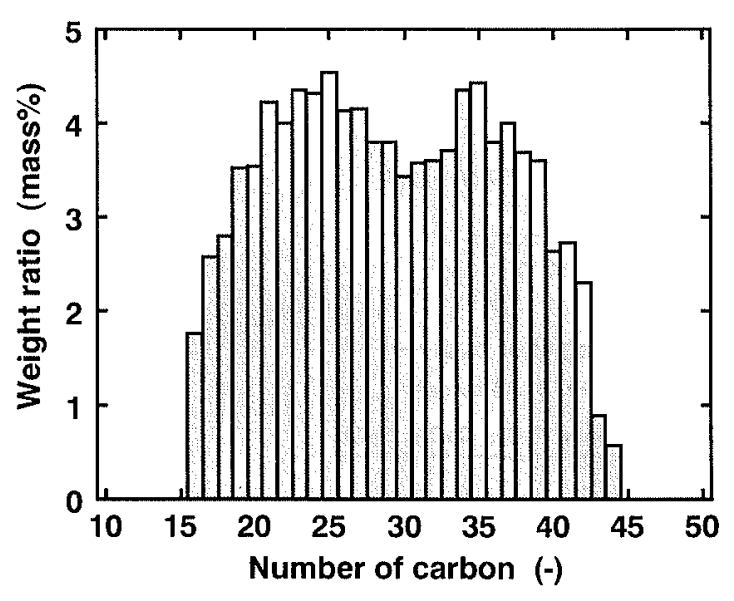

Fig. 10. Number of carbon of tar in dust.

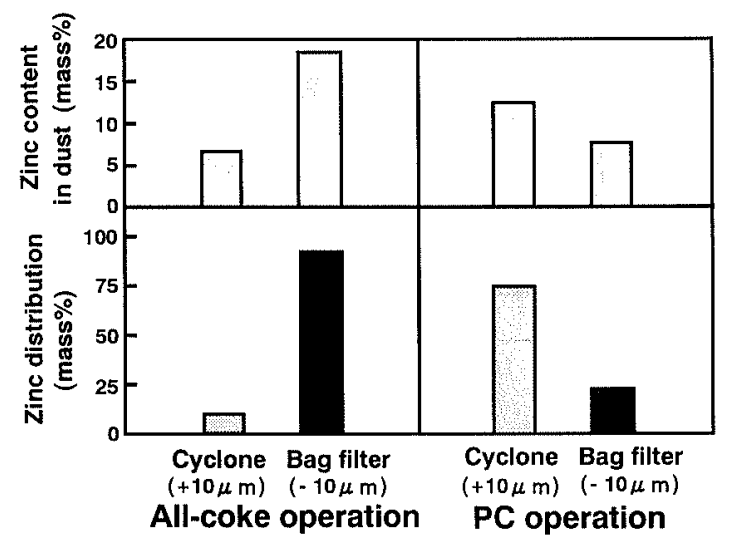

Fig. 11. Zinc balance in cyclone and bag filter dust. (zinc input: $5 \mathrm{~kg} / \mathrm{t})$

sists of heavy hydrocarbons with low vapor pressure derived from decomposition of plastics in low temperature. Therefore, for long term operation, top charge of plastics could possibly cause serious trouble in the dust cleaning system due to the deposition of tar. It is desired that plastics should be injected through the raceway, so that they can instantaneously decompose in the hot gas temperature condition over $2000^{\circ} \mathrm{C}$.

\section{Behavior of Zinc in the Shaft Furnace}

Collected steel scrap generally contains zinc. Zinc charged into a blast furnace with the raw materials vaporizes and circulates within the furnace. Frequently, it adheres to the wall and eventually causes operating problem. It is feared that a similar phenomenon may occur in this scrap melting process.

Then, scrap containing $5 \mathrm{~kg} / \mathrm{t}$ of zinc was continuously charged during all-coke and pulverized coal injection operation so as to investigate zinc behavior in the experimental furnace. Sample dust from the furnace top gas was collected, and in-furnace dust was collected with the horizontal probe, and zinc distribution in the dust from the furnace was calculated to be shown in Fig. 11. It was found that the form of zinc in the dusts sampled from the in-furnace was basically metallic zinc and that that of zinc in the dust sampled at the furnace top was mainly zinc oxides. Furthermore, as is obvious in Fig.

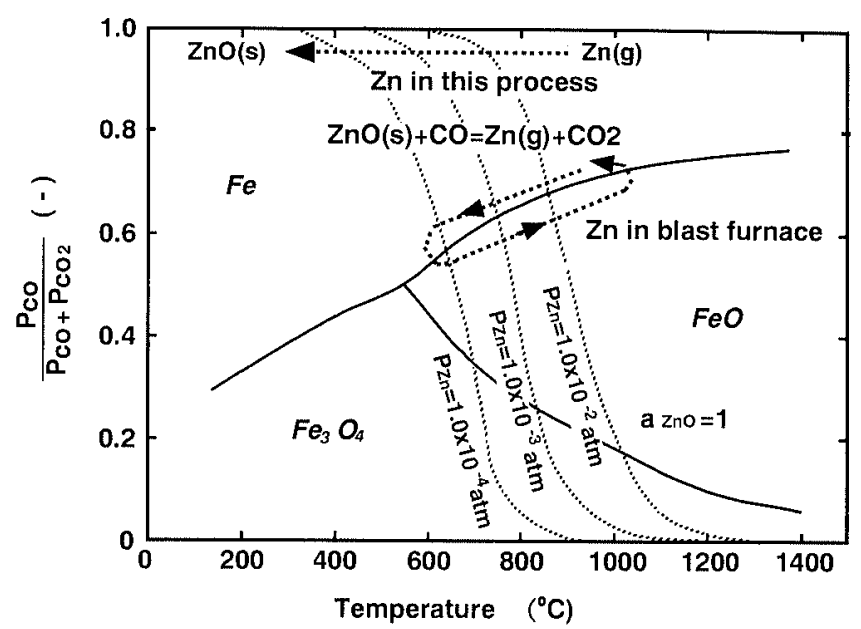

Fig. 12. Zinc behavior in this process and blast furnace.

11 , in all-coke operation almost all the zinc is recovered within dust collected by the bag filter (under $10 \mu \mathrm{m}$ ). On the other hand, in pulverized coal operation, much of the zinc was recognized as relatively coarse (above $10 \mu \mathrm{m}$ ) particles collected at the cyclone. In this case, it is estimated that the zinc oxides are especially likely to adhere to the char particles that result from pulverized coal.

An examination of wall and inner surface within the furnace and uptakes after operation revealed no zinc adhesion. The penetration of zinc into the refractory in the shaft part was not observed. In this process, the oxidation degree of the top gas is very low compared with a blast furnace, and it is almost constant within the furnace, because the reducing process like in a blast furnace does not occur. Thus, it was estimated that zinc was not oxidized in the furnace and did not circulate in the experimental furnace. Metallic zinc vapor was just oxidized at the top of the furnace. This behavior can be represented in Fig. 12, compared with blast furnace. In the case of a blast furnace, since the oxidation degree of the gas in the shaft is close to the equilibrium of $\mathrm{Fe} / \mathrm{FeO}$, zinc vapor tends to be oxidized in the shaft as shown in Fig. 12. Then, it is considered that zinc circulates in the furnace. However, in this process, zinc is not susceptible to circulation in the furnace due to the above reason. Consequently, it was considered that zinc oxidized at the top of the furnace was adsorbed by other dusts like char and carried over with these top gas dusts, and no accumulation occurred.

\section{Investigation on Productivity}

\subsection{Influence of Scrap Size}

The heating rate of steel scrap can be influenced by their size and bulk density. As a result, the temperature distribution along the height of the furnace and the productivity also are possibly affected by them. Thus, the temperature distribution in the furnace was measured by the horizontal probe while varying the size and bulk density of the scrap, keeping the productivity at 10 to $12 \mathrm{t} / \mathrm{dm}^{3}$ level. Figure 13 shows the temperature distribution that resulted from changing the size of scrap from $30-60 \mathrm{~mm}$ (shredded) to $200 \mathrm{~mm}$ (heavy plate) and the 


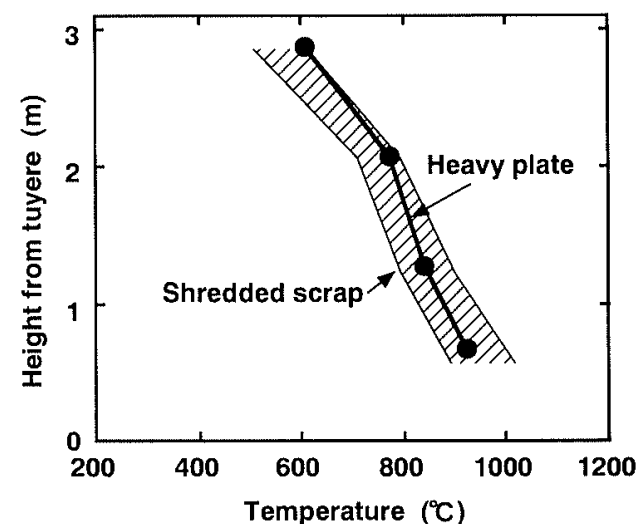

Fig. 13. Temperature distribution in furnace changing scrap size.

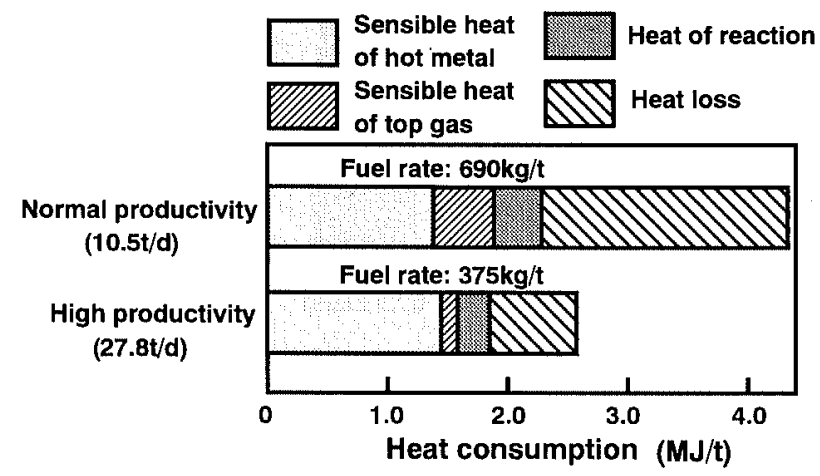

Fig. 14. Heat balance of high productivity operation compared with normal productivity operation.

bulk density of scrap from 1.9 to $3.4 \mathrm{~kg} / \mathrm{m}^{3}$. According to the results, the temperature distribution in the furnace was basically much different from that of a blast furnace, and gives essentially straight line. It is found that both cases in Fig. 13 stayed nearly the same, unaffected by the scrap size. Consequently, it was estimated that the shape and bulk density has little influence on the heating rate within these experimental conditions.

\subsection{Flooding Phenomenon}

To determine the upper limit on productivity, the production rate of hot metal was gradually increased up to $28 \mathrm{t} / \mathrm{d}$ under the same size scrap condition of the standard. During this change, favorable operation result could be maintained, and fuel rate became under $400 \mathrm{~kg} / \mathrm{t}$ through the decrease of heat-loss. The heat balance at high productivity is shown in Fig. 14. In the same manner as in a cupola, this experimental furnace could reach higher production rate than in a blast furnace due to the low slag rate. Namely, slag rate in this experimental furnace is about $100 \mathrm{~kg} / \mathrm{t}$ at normal productivity level. Next, the production limit was examined from the viewpoint of flooding phenomenon in the lower part of the furnace. Figure 15 shows the slag and metal dripping conditions in this process. At the same time, the flooding line and the actual data regarding the maximum productivity recorded in Keihin No. 2 Blast Furnace that seems to be upper limit were plotted in Fig. 15.8) Generally, slag dripping condition affects the flooding phenomena. In consideration of these flooding phenomena in the lower part, although the production rate of

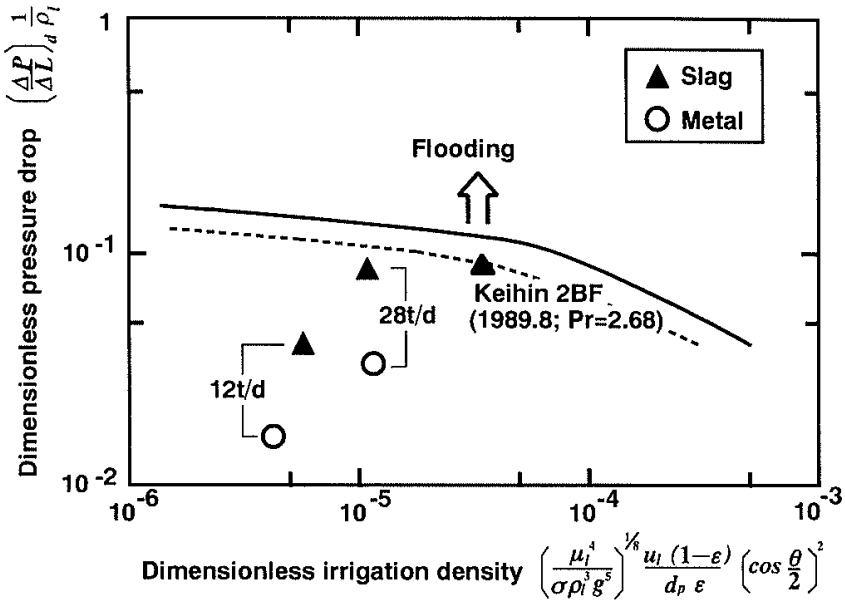

Fig. 15. Flooding conditions in the experimental furnace.

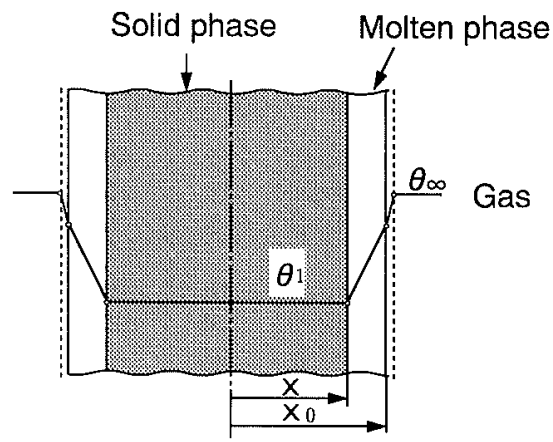

$\rho 1 \Delta \mathrm{HAdx} / \mathrm{dt}=-\mathrm{h} A\left(\theta_{\infty}-\theta_{1}\right)$

Fig. 16. Melting model of steel plate of scrap and its mathematical formation. A: surface area $\left(\mathrm{m}^{2}\right), \Delta H$ : heat of fusion $(\mathrm{J} / \mathrm{kg}), h$ : over-all heat transfer coefficient $(\mathrm{W} / \mathrm{mK}), t$ : time (s), $x$ : direction $(\mathrm{m}), 0$ : temperature $(K), \rho_{1}$ : density of solid $\left(\mathrm{kg} / \mathrm{m}^{3}\right)$

$28 \mathrm{t} / \mathrm{d}$ was easily recorded in the experimental furnace, this value should be very close to the actual limit.

Moreover, the possibility on a limitation from fluidization conditions at the throat was also examined. It was found that there is sufficient leeway at the throat to prevent any such limitation.

\subsection{Relation between Productivity and Scrap Plate Thickness}

The relation between the melting time determined by scrap thickness and the productivity was examined, since melting time of scrap in the lower part of the furnace is dependent on scrap thickness and could finally influence on the productivity. The melting model of plate in one dimension can be represented in Fig. 16. In this case, it is assumed that heat supplied from gas is consumed only by the melting phenomenon of steel and the carburization effect into the solid iron can be neglected due to the relative rate of melting rate by heating to the carburization rate. Fundamental equation is also shown in Fig. 16.9) Finally, the melting time $t_{\mathrm{E}}$, derived from the fundamental equation in Fig. 16, can be represented as follows:

$$
t_{\mathrm{E}}=\rho_{1} \Delta H X_{0} / h\left(\theta_{\infty}-\theta_{1}\right)
$$

By substituting the actual value of plate thickness, gas temperature and properties of steel scrap into Eq. (1), 

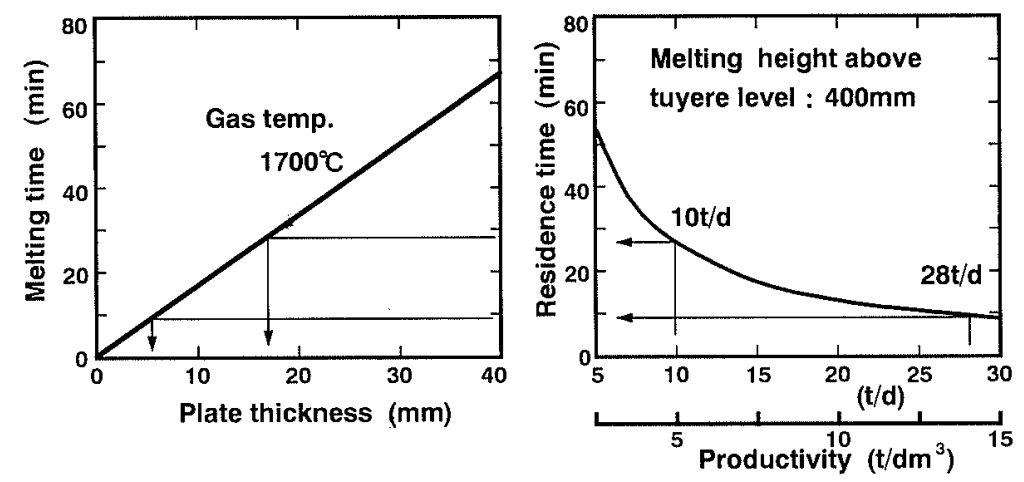

Fig. 17. Relation among productivity, residence time and plate thickness.

Table 5. Operating conditions of commercial process.

\begin{tabular}{|c|c|c|}
\hline $\begin{array}{ll}\begin{array}{ll}\text { Fuel } \\
\text { Coke }\end{array} & (\mathrm{kg} / \mathrm{t}) \\
\text { PC } & (\mathrm{kg} / \mathrm{t}) \\
\text { Plastics } & (\mathrm{kg} / \mathrm{t}) \\
\end{array}$ & $\begin{array}{c}255 \\
200 \\
-\end{array}$ & $\begin{array}{r}140 \\
55 \\
120\end{array}$ \\
\hline $\begin{array}{l}\text { Flux } \\
\text { Lime stone }(\mathrm{kg} / \mathrm{t}) \\
\text { Silica stone }(\mathrm{kg} / \mathrm{t}) \\
\text { Serpentine }(\mathrm{kg} / \mathrm{t})\end{array}$ & $\begin{array}{l}95 \\
25 \\
15\end{array}$ & $\begin{array}{r}40 \\
15 \\
5\end{array}$ \\
\hline $\begin{array}{ll}\text { Blast } & \\
\text { Air } & \left(\mathrm{Nm}^{3} / \mathrm{t}\right) \\
\text { Oxygen } & \left(\mathrm{Nm}^{3} / \mathrm{t}\right) \\
\text { Steam } & \left(\mathrm{Nm}^{3} / \mathrm{t}\right)\end{array}$ & $\begin{array}{r}16 \\
235 \\
70\end{array}$ & $\begin{array}{r}28 \\
190 \\
-\end{array}$ \\
\hline Slag rate $(\mathrm{kg} / \mathrm{t})$ & 125 & 55 \\
\hline \begin{tabular}{ll}
\multicolumn{2}{l|}{ Top gas } \\
Temp. $\left({ }^{\circ} \mathrm{C}\right)$ \\
$\mathrm{CO} \quad(\mathrm{vol} \%)$ \\
$\mathrm{H}_{2} \quad(\mathrm{vol} \%)$ \\
$\mathrm{N}_{2} \quad(\mathrm{vol} \%)$ \\
\multicolumn{2}{c}{ Calorie $\left(\mathrm{MJ} / \mathrm{Nm}^{3}\right)$}
\end{tabular} & $\begin{array}{r}150 \\
73.5 \\
22.6 \\
2.1 \\
11.7\end{array}$ & $\begin{array}{r}150 \\
62.6 \\
32.9 \\
3.7 \\
11.4\end{array}$ \\
\hline
\end{tabular}

Theoretical flame temp.:2200 20

the relation between the plate thickness and the melting time can be obtained. The average gas temperature between the initial level to the completion level for melting in the lower part of the furnace is assumed to be $1700^{\circ} \mathrm{C}$. The residence time of scrap between tuyere level and initial melting level gives enough time to melt scrap in the lower part of the furnace. Here, the initial melting level confirmed by the dissection of the furnace after the operation was $0.4 \mathrm{~m}$ above the tuyere level. The residence time in the melting zone can be calculated from the descending velocity determined by the productivity and the distance between tuyere level and initial melting level. Under these assumptions, the relation among plate thickness, melting time and productivity can be represented as shown in Fig. 17. From Fig. 17, it is found that a productivity condition of $28 \mathrm{t} / \mathrm{d}\left(14 \mathrm{t} / \mathrm{dm}^{3}\right)$ is just equivalent to the melting time of the shredded plate of $5 \mathrm{~mm}$ thickness, keeping the melting level constant. In the same manner, the thickness of about $20 \mathrm{~mm}$ plate corresponds to the productivity of $10 \mathrm{t} / \mathrm{d}\left(5 \mathrm{t} / \mathrm{dm}^{3}\right)$. Therefore, as long as shredded plates of $5 \mathrm{~mm}$ thickness are used as charged scrap of standard, the production limit in terms of the effective inner volume comes to $14 \mathrm{t} / \mathrm{dm}^{3}$, which is equivalent to the upper limit determined by flooding.

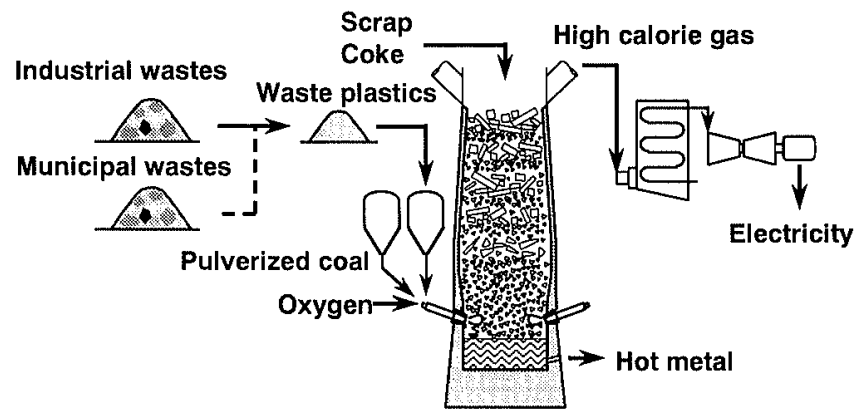

Fig. 18. Commercial process of the scrap melting shaft furnace.

\section{Investigation on Commercial Process}

On the basis of the results described above, the operating conditions in the commercial process can be estimated as shown in Table 5. The schematic representation of the commercial process is shown in Fig. 18. This process utilizes scrap as an iron source and waste plastics generated from nearby cities as fuels to not only melt the scrap but also to generate gas suitable for combustion in a power plant. Moreover, a much higher productivity than in a blast furnace can be attained.

In Table 5, the flame temperature in the raceway and the top gas temperature are maintained at the same level as those in a conventional blast furnace, and steam is used to control the flame temperature. A small amount of air is used for carrier gas of pulverized coal and plastics. The top gas recovered with this process has a much higher calorific value of about $11.7 \mathrm{MJ} / \mathrm{Nm}^{3}$ than a conventional blast furnace. The addition of plastics in partial replacement of pulverized coal increases the amount of heat given off by combustion and reduces the amount of slag, thereby lowering fuel requirements.

In future, this process will play a practical role in recycling wastes from nearby cities in steelworks.

\section{Conclusion}

A process in which a large amount of pulverized coal and waste plastics are used as a heat source for scrap melting was newly proposed. The feasibility of the process was confirmed with an experimental furnace and process characteristics were also examined. The main results are as follows:

(1) Pulverized coal and plastics could be effectively used to melt steel scrap with a shaft furnace, and an 
oxygen burner enabled the injection of large amounts of such fuels. Injection rate of $300 \mathrm{~kg} / \mathrm{t}$ pulverized coal and $150 \mathrm{~kg} / \mathrm{t}$ plastics were successfully attained.

(2) Combustion efficiency of coarse plastics was much higher than pulverized coal in spite of its large diameter. In the case of plastics injection, particle size has little influence on combustion efficiency, and it was estimated that the circulation of plastics in the raceway enables the high combustibility of coarse plastics.

(3) During the injection of PVC, hydrogen chloride concentration in the gas at the gas cleaning system was about $5 \mathrm{ppm}$ due to the reaction of hydrogen chloride with ferrous compounds and alkali metals in the dust.

(4) The top charge of plastics was tried and compared with the injection of plastics through the tuyere, and it was found that plastics charged to the top generate tar due to decomposition of plastics in the shaft.

(5) Zinc charged into the furnace was carried over as zinc oxide with upward gas, and no adhesion was recognized within the furnace because of the low gas oxidation degree.

(6) On the basis of flooding phenomenon and melting rate in the lower part of the furnace, maximum productivity of this process was estimated to be $14 \mathrm{t} / \mathrm{dm}^{3}$.

(7) The operating conditions for a commercial scale process were investigated on the basis of these experimental results.

\section{REFERENCES}

1) T. Ishino: Tetsu-to-Hagané, 79 (1993), N343.

2) Y. Kamei, T. Miyazaki and H. Yamaoka: Tetsu-to-Hagané, 79 (1993), 139.

3) J. Janz and W. Weiss: Proc. of 3rd European Ironmaking Cong., CRM-VDEh, Gent, (1996), 114.

4) T. Furukawa, H. Mitsufuji, M. Matsuura and Y. Ohno: Rev. Metall., Cah. Inf. Tech., (1990), 549.

5) T. Ariyama, Y. Yamakawa and M. Sato: Tetsu-to-Hagané, 81 (1995), 703.

6) M. Asanuma and T. Ariyama: CAMP-ISIJ, 9 (1996), 755.

7) M. Asanuma, T. Ariyama, M. Sato, R. Murai and Y. Asakawa: CAMP-ISIJ, 9 (1996), 754

8) R. Nakajima, B. Iino, H. Hotta, H. Ito, S. Furuya and I. Ohkochi: CAMP-ISIJ, 3 (1990), 69.

9) VDI-WARMEATLAS, VDI-Verlag GmbH, Düsseldorf, (1984), Ecl2. 